\title{
China After 35 Years of Economic Transition Editorial
}

\author{
Guglielmo Maria Caporale \\ Brunel University London, CESifo and DIW Berlin \\ Kefei You \\ London Metropolitan University
}

This special section of China Economic Review includes ten selected papers from a conference on "China after 35 Years of Economic Transition", held in London at London Metropolitan Business School on 8-9 May 2014. The conference provided a platform for experts, academics, and policymakers to exchange their in-depth insights into all aspects of the Chinese economic and social transformation since 1978. It was also an opportunity to evaluate the prospects for the decades ahead. Keynote speakers at the conference included Mr Xianhong Deng, Deputy Governor of the State Administration of Foreign Exchange (SAFE) of China, and Dr Linda Yueh, Director of the China Growth Centre at Oxford University and the BBC Chief Business Correspondent.

Conference attendees came from universities and research institutions in China, the UK, Europe, and the US, as well as from central banks and international organisations such as the European Central Bank (ECB) and the International Monetary Fund (IMF). The research papers presented covered a wide range of important issues concerning China such as economic growth, financial development, trade, exchange rate policy, capital flows, urbanisation, environment and health.

The studies selected for this special section are a carefully selected subset of conference papers submitted for publication, and all submissions were subjected to China Economic Review's double-blind review process. The selected papers fall into two 
main categories, focusing on the domestic economy and linkages between China and the rest of the world respectively.

The first paper belonging to the domestic-economy category, by Atella, Brugiavini and Pace, evaluates the impact of the 1998 Chinese health care reform on out-of-pocket expenditure and saving. It employs data collected by the Chinese Household Income Project (CHIP), through a series of questionnaire-based interviews conducted in urban areas in 1995 and 2002. The analysis takes into account unobserved heterogeneity (health status) and suggests that out-of-pocket expenses increase more for individuals with poor health status, whilst the saving rate increases only for individuals with good health status.

The paper by Fungacova and Weill analyses instead financial inclusion using data from the World Bank Global Findex database for 2011. It finds a high level of financial inclusion in China as indicated by a greater use of formal account and formal saving than in the other BRICS. Financial exclusion, i.e. not having a formal account, is mainly voluntary. Borrowing through family or friends is the most common way of obtaining credit in all the BRICS countries. However, in China other channels for borrowing are not very commonly used; also, higher income, better education, being a man, and being older are associated with greater use of formal accounts and credit. Income and education affect the use of alternative sources of borrowing. On the whole, financial inclusion does not seem to be a major problem in China, but the limited use of formal credit is likely to be a challenge for further economic development.

The study by Bohl examines whether the introduction of Chinese stock index futures had an impact on the volatility of the underlying spot market. Specifically, it estimates several GARCH models and compares the findings for mainland China with Chinese index futures traded in Singapore and Hong Kong. The results indicate that Chinese index futures decrease spot market volatility in all three spot markets considered, but not in the companion index futures markets in Hong Kong and Singapore. China's stock market is relatively young and largely dominated by private retail investors. 
Nevertheless, the evidence supports the stabilisation hypothesis normally valid for mature markets.

The contribution by Jiang, Zhu and Green uses instead a unique input-output table that distinguishes trade mode and firm ownership to examine the relative advantage of foreign-invested enterprises (FIEs) in mainland China. These are found to outperform Chinese owned enterprises (COEs) in terms of total energy intensity by $16.97 \%, 14.97 \%$ and $42.89 \%$, respectively, for the processing, non-processing and overall production in the industrial sector. Further decompositions show that structural differences across industries (and trade mode) have a positive effect and account for $65.33 \%, 26.28 \%$ and $81.93 \%$ of the relative advantage of FIEs for processing, non-processing and overall production. Failure to capture heterogeneity across trade mode may distort the results regarding the energy efficiency advantage of FIEs over COEs in China.

The final paper on domestic issues, by Yua and Ashtonb, investigates the board leadership structure of Chinese public listed companies. Specifically, it examines its relationship with firm performance and the expense ratio, using propensity score matching methods for Chinese PLCs from 2003-2010. The analysis indicates that, while CEO duality is not related to companies' profitability ratios, it is linked to a higher expense ratio compared to matched companies with a separate board leadership structure. Consequently, corporate governance in the form of a separate board leadership structure is effective in reducing agency costs for Chinese PLCs.

The first of the studies with an international dimension, by You and Solomon, examines how China's domestic investment responds to its fast rising foreign direct investment (FDI) outflows at industry level. Government support is taken into account given the important role it has played. An accelerator model is estimated using the system-Generalised Method of Moments (GMM). The findings suggest that domestic investment responds positively to outward FDI in China. Furthermore, FDI outflows influence domestic investment differently depending on the level of 
government support in specific industries, i.e. much more strongly in state dominated industries than in the non-state dominated ones.

The paper by Caporale, Sova and Sova analyses instead trade flows between China and its main trade partners in Asia, North America and Europe, with the aim of establishing whether more trade has resulted in industrial adjustment and changes in China's trade patterns. The analysis uses both economic indicators and a gravity model; the latter is estimated using the fixed effect vector decomposition (FEVD) technique that explicitly takes into account panel heterogeneity. The results confirm the significant change in China's trading structure, with a clear shift from resourceand labour-intensive to capital- and technology-intensive exports. It appears that there have been both static and dynamic benefits of trade boosting economic growth.

China's outward direct investment (ODI) in Latin America and the Caribbean (which is entering into the second phase with diversification of economic actors and industries of investment) is the focus of the study by Lin. The analysis extracts the approved projects by the Chinese Ministry of Commerce from its online database between 2003 and 2012, and fits a random effect negative binomial regression model. The presented evidence suggests a significant difference between Chinese public and private investors in their ODI motivations and the way they perceive risk, consistently with previous studies. Further, the host country institutions are not purely ownershipspecific, but contingent on industries in which they tend to invest, and the direction of the institutional effect varies across sectors and firm types.

The relationship between the real exchange rate (RER) and economic growth in China is analysed in the paper by Tang by estimating a cointegrated VAR (CVAR) model. The conclusion is that the Chinese economy has not benefited from the lower exchange rate of the $\mathrm{RMB}$, and that this is not directly linked to long-run growth. Important growth drivers are instead exports and inflows of foreign capital. In addition, the 2005 RMB policy reform did not have any significant impact on the RER, but contributed to steady economic growth: after the 2008 world financial crisis, the RMB exchange 
rate was largely dependent on the inflow of foreign capital, rather than the slow increase in foreign trade. The policy implication is that for China a managed floating exchange rate policy might still be recommendable, with only limited adjustments to the currency's daily floating range in response to pressures from trade partners.

Finally, the study by Caporale, Menla Ali and Spagnolo investigates the time varying impact of oil price uncertainty on stock prices in China using weekly data on ten sectoral indices over the period January 1997-February 2014, and estimating a bivariate VARGARCH- in-mean model. The results show that oil price volatility affects stock returns positively during periods characterised by demand-side shocks in all cases except the Consumer Services, Financials, and Oil and Gas sectors. The latter two exhibit a negative response to oil price uncertainty during periods with supply-side shocks, whilst this is insignificant during periods with precautionary demand shocks. The implication is that investors cannot use Chinese stocks and oil to hedge and diversify, with the exception of Financials and Oil and Gas sectors during periods characterised by supply-side shocks, and Consumer Services in all periods.

On the whole, the papers included in this special section provide a comprehensive assessment of the transition process which has taken place in China in the last 35 years by using state-of-the art econometric methods to obtain new empirical evidence on a number of issues directly relevant to academics as well as policy makers and markets participants. All studies also highlight the policy implications of the analysis and make an important contribution to the current debate on the role of China in the global economy. The key message arising is that while China has achieved an impressive transformation in the past 35 years, great challenges lay ahead concerning various aspects of China's future, especially the re-structuring of the economy to make it more dependent on consumption rather than on exports, promoting productivity and innovation as growth drivers, and establishing stable and strong institutional foundations. 